\title{
Corrigendum
}

\section{Characterization of human kallikrein 6/prostease $M$ expression in ovarian cancer}

\section{Ni, W Zhang, K-C Huang, Y Wang, S-K Ng, SC Mok, RS Berkowitz and S-W Ng}

British Journal of Cancer (2005) 92, 983. doi:I0.1038/sj.bjc.6602508 www.bjcancer.com

(c) 2005 Cancer Research UK

Correction to: British Journal of Cancer (2004) 91, 725-731. doi:10.1038/sj.bjc.6602041

With reference to the above article published in the British Journal of Cancer, the authors wish to make the following statement:
Although one of us participated in the work that resulted in the first publication about kallikrein 6/protease $M$, we were not physically involved in the first cloning of kallikrein 6 cDNA. Nevertheless, this does not have any influence on the conclusions of this article. 